\title{
El águila, el jaguar y la serpiente: Miguel Covarrubias y el debate del difusionismo
}

\section{The Eagle, the Jaguar and the Serpent: Miguel Covarrubias and the Diffusionism Debate}

Artículo recibido el 22 de abril de 20I8; devuelto para revisión el 22 de octubre de 2018 ; aceptado el 23 de febrero de 20I9; http://dx.doi.org/IO.2220I/iie.18703062e.20I9.monor.2710.

Rita Eder Instituto de Investigaciones Estéticas, Universidad Nacional Autónoma de México; eder.rita@gmail.com; https://orcid.org/oooo-ooor-65788204 .

Líneas de investigación arte moderno y contemporáneo en México y América Latina, historiografía del arte, teoría del arte.

Publicaciones Narraciones: pequeñas historias y grandes relatos en la pintura de Antonio Ruiz (1935-1949) (México: Instituto de Investigaciones EstéticasUNAM, 20I7).

Resumen Este trabajo analiza la adhesión de Covarrubias a las hipótesis de contactos culturales y raciales entre el Pacífico, las Américas y el Viejo Mundo (China e India). Las investigaciones sobre el tema que más le llamaron la atención provenían de especialistas europeos y estadounidenses como Robert Heine-Geldern, Gordon Eckholm y Carl Schuster, las cuales influyeron en la redacción del primer tomo de su obra: El águila, el jaguar y la serpiente: arte indígena en las Américas (1954). En las primeras páginas de este libro, el autor se declara culpable de "desviaciones difusionistas subversivas" y menciona con entusiasmo el XXIX Congreso de Americanistas, celebrado en el American Museum of Natural History de Nueva York en septiembre de 1949, foro donde se debatieron ampliamente diversos temas y problemas relativos al difusionismo. Al mismo tiempo se montó la exposición "Across the Pacific" (A lo largo del Pacífico), cuyo objetivo era mostrar — por medio de objetos artísticos, rituales y cotidianos-, paralelismos encaminados a comprobar hipótesis de contacto. La muestra sugirió una forma de organizar la cultura material dentro de la diversidad y enfatizó la importancia de los estudios comparativos por medio de la forma. Para Covarrubias, estas ideas ya habían sido desarrolladas parcialmente en los mapas del Pacífico (1939) y en su libro Mexico South (1946). Sin embargo, el énfasis sobre lo visual/estructural que ocurrió 
en el XXIX Congreso de Americanistas dejó una huella mayor con relación al contacto entre culturas que Covarrubias pudo desarrollar más ampliamente en Arte indígena de las Américas.

Palabras clave Miguel Covarrubias; El águila, el jaguar y la serpiente, Robert HeineGeldern; Gordon Eckholm; Carl Schuster; difusionismo; contactos transpacíficos; estudios comparativos, "A lo largo del Pacífico".

Abstract This article analyzes Covarrubias adhesion to Gordon Eckholm's and Robert Heine-Geldern's expertise on cultural contacts between The Pacific, the Americas and South East Asia. It also focuses on the lesser known impact of Carl Schuster on the first volume of Covarrubias's work: The Eagle, the Jaguar and the Serpent: Indian Art in the Americas. In the first pages of this book he declares his interest in the so called "subversive diffusionism" and mentions enthusiastically the XXIXth Americanist Congress held in September of 1949 at the American Museum of Natural History in New York City. A strong debate on Diffusionism took place in a series of sessions with the intent to probe cultural and racial contacts between the new and the old world (China and Japan). At the same time an exhibition, "Across the Pacific", organized by the anthropologist and curator of the American Museum of Natural History, Gordon Eckholm, meant to compare ritual and artistic objects to reinforce the idea of cultural contacts between distant geographical areas. The exhibit suggested a way of organizing material culture within a diversity of themes and motifs that were of interest to Covarrubias and influenced the writing of his book: The Eagle, the Jaguar and the Serpent: Indian Art of the Americas (1954).

Keywords Miguel Covarrubias; The Eagle, the Jaguar and the Serpent; Robert Heine-Geldern; Gordon Eckholm; Diffusionism; transpacific contacts; Carl Schuster; comparative studies; "Across the Pacific". 
DOI: https://doi.org/10.22201/iie.18703062e.2019.mono1.2710

\author{
RITA EDER
}

INSTITUTO DE INVESTIGACIONES ESTÉTICAS, UNAM

\title{
El águila, el jaguar y la serpiente: Miguel Covarrubias y el debate del difusionismo
}

I detonador de este trabajo fue la polémica acerca de la validez de $E l$
águila, el jaguar y la serpiente: arte indigena americano de la autoría de
Miguel Covarrubias (I904-1957). El libro, publicado por primera vez en
inglés (I954) por la editorial Alfred Knopf de Nueva York, fue pionero en su
tema, ${ }^{\mathrm{I}}$ y durante las décadas de los años cincuenta y sesenta tuvo buena re-
cepción entre especialistas y legos. ${ }^{2}$ En los años setenta del siglo xx, esta obra
fue cuestionada en el medio académico estadounidense por "difusionista", un
término problemático para los americanistas y un tema visto críticamente por

I. Hay antecedentes de la puesta en valor del arte indígena de Norteamérica desde principios del siglo xx a partir de exposiciones y catálogos. Destaca Indian Art of the United States, con la curaduría a cargo de René d'Harnoncourt y Frederick Douglas (Nueva York, момA 194I). La muestra constó de I,Ooo piezas y la antigüedad de las mismas se remontaba a I,500 ańos. El discurso alrededor de la exposición fue el de su valoración como objetos artísticos; el de la expresión el redescubrimiento del pasado y un rechazo a las corrientes racistas de la Europa nazi.

2. Esta obra, que intentaba un enfoque comparativo y una valoración estética del arte indígena tuvo en general una buena recepción y fue reseñada en periódicos como el New York Times, Chicago Tribune, Boston Herald y en revistas como el New Yorker y Time en forma favorable. También tuvo presencia entre los especialistas de la época como Robert Goldwater en su artículo "The not so Primitive", dedicado a los estudios publicados en los años cincuenta sobre las artes del Pacífico, África y las Américas. Estos materiales se encuentran en el Harry Ransom Center de la Universidad de Austin en Texas (Folder I33I.3: Knopf: Covarrubias, Miguel). En el artículo de Janet Berlo: "Transgressing Borders. Miguel Covarrubias and the Developments of Native American Art History” (Carolyn Kastner, ed., Miguel Covarrubias. Drawing a Cosmopolitan Line [Austin: University of Texas, 20I4], 76-99), hay un seguimiento puntual del proceso de publicación de esta obra. Consúltese particularmente las páginas 8I-82 de este artículo y las notas 40-47. 
algunos antropólogos. ${ }^{3}$ Los distintos hallazgos de la antigüedad del hombre americano desestabilizaron, aunque no fueron los únicos factores que interfirieron, en el interés por los contactos transpacíficos. Disminuyeron las investigaciones sobre el tema, en particular aquellas que se realizaban entre los años cuarenta y principios de los setenta en el Departamento de Antropología del American Museum of Natural History, mientras estuvo bajo la dirección del antropólogo y curador Gordon Eckholm (190I-1989).

El término difusionista y la conceptualización del mismo es complejo por la diversidad de perspectivas y corrientes de pensamiento que lo conforman, asunto que debe considerarse al revisar el libro de Covarrubias en el que me detendré a lo largo de este texto. El autor formula cuidadosamente sus hipótesis y es muy consciente del conocimiento como un producto de su tiempo, lo concibe como una planta en constante cambio, metáfora apreciada por los teóricos de la vida de las formas.

\section{Inicios}

El American Museum of Natural History de Nueva York conocido en el mundo por la gran sala de los dinosaurios y las grandes colecciones de objetos culturales y artísticos, ocupa un lugar importante en la obra de Miguel Covarrubias, quien radicó una buena parte de su vida en esa ciudad. ${ }^{4}$ Hay suficiente

3. Marvin Harris, El desarrollo de la teoría antropológica: una historia de las teorías de la cultura (Madrid: Siglo XXI, I968 [Ia. edición española 1979]) (revisado y reeditado en 200I). Véase el capítulo dedicado al difusionismo, 323-339.

4. Miguel Covarrubias llegó a Nueva York en 1923 a sugerencia de José Juan Tablada, sólo tenía entonces I9 años. El poeta, consciente del talento de Covarrubias como dibujante, pensó que pronto obtendría trabajo en la floreciente industria de las revistas culturales como Vanity Fair y The New Yorker. No se equivocó Tablada, al poco tiempo, Covarrubias trabajaría para ambas publicaciones durante varios años. Su fama como caricaturista le permitió penetrar diversos círculos de la élite neoyorkina en la que hizo muchos amigos, entre ellos Karl Van Vechten, quien lo llevaría al Harlem de entonces, en el que ya despuntaba una intensa vida cultural y artística conocida como el "Harlem Renaissance". De esta experiencia nacería el libro Negro Drawings, publicado en 1927. En los Estados Unidos, principalmente en Nueva York y San Francisco, Covarrubias haría una brillante carrera como dibujante, caricaturista, ilustrador, antropólogo y cartógrafo. Al dejar Nueva York, ya en forma permanente, a principios de los años cincuenta por problemas con el macartismo y el comité for un-American activities (Adriana Williams, Miguel Covarrubias, Austin: Texas University Press, 1994), I88-I90, permanecería en contacto con sus conocidos y amigos, 
evidencia de su relación con este museo, ello permite entender algunos de los aspectos de su trayectoria intelectual y visual. Ahí estableció una buena relación con los departamentos de investigación y curaduría que tanto influirían en su obra El águila, el jaguar y la serpiente. Arte indigena de las Américas (1954).5

\section{"Desviaciones difusionistas subversivas"}

Llegué al emblemático museo —ubicado entre las calles 77 y 8I en Central Park West - con el deseo de observar con mayor detalle algunos objetos que interesaron a Covarrubias y, sobre todo, para desentrañar un complejo párrafo que el dibujante y antropólogo destacaría en las primeras páginas del primer tomo de Arte indígena americano. En él plantea su intención de hacer conexiones entre las culturas indígenas a lo largo del continente americano y así mostrar sus afinidades con la producción material y artística del sudeste asiático y las civilizaciones surgidas en las islas y las costas del Gran Pacífico. En unas cuantas líneas revela la importancia que sobre sus hipótesis tuvieron tanto el XXIX Congreso de Americanistas — celebrado en septiembre de 1949 en el American Museum of Natural History- como la exposición que acompañó dicho congreso con el título "Across the Pacific", y un subtítulo significativo: " ¿Contribuyeron las antiguas civilizaciones del Extremo Oriente a las civilizaciones indoamericanas?” En ambos eventos se presentaron, según atestigua Covarrubias, un conjunto de paralelismos útiles para argumentar el tema de las relaciones culturales transpacíficas:

La posibilidad de diversas influencias y contactos en América, Asia oriental y el Pacífico Sur es cada vez más tangible. Se aprecia una tentadora semejanza entre los estilos artísticos y el espíritu de algunas culturas indoamericanas y China, semejanzas ya señaladas por historiadores del arte y arqueólogos tan serios como Fenollosa, Osvald Siren, Leonhard Adam, Berthold Laufer, H. G. Creel, Carl Hentze y en particular Gordon Eckholm, Carl Schuster y el doctor Robert Heine-Geldern [...]. Siempre

continuaría con diversos proyectos, entre ellos, una importante colaboración con el Museum of Primitive Art que se encuentra en esa ciudad.

5. El título en inglés de este libro es: The Eagle, the Jaguar and the Serpent: Indian Art of the Americas. La traducción al español de Sol Arguedas es El águila, el jaguar y la serpiente: arte indígena americano. Arguedas también tradujo el t. 2: Arte indígena de México y Centroamérica (Ciudad de México: Universidad Nacional Autónoma de México, 196I). 
me han llamado la atención las similitudes entre los conceptos y estilos de las artes de América, Asia Oriental y de los mares del sur, y me confieso culpable de desviaciones difusionistas subversivas. Las teorías de Rivet, Heine-Geldern y Gladwin, y otros han ayudado a esclarecer mis propias impresiones respecto a los contactos transpacíficos. ${ }^{6}$

Llama la atención, en el contexto de este párrafo, la mención a sus "posiciones difusionistas subversivas", lo que invita a pensar dónde se ubica Covarrubias en las controvertidas teorías del difusionismo y sus variantes principales en el momento que escribió este libro.

El difusionismo, en principio, afirma la importancia de la dispersión desde centros emisores de invenciones técnicas, artísticas, agrícolas y de todo proceso civilizatorio. Se entiende que esto no anula la posibilidad de diferenciar cada grupo humano, pero afirma la relevancia de establecer los contactos entre culturas y realizar estudios comparativos. Es bien sabido que en la conformación del difusionismo hay varias escuelas que surgieron en Europa, principalmente en Alemania e Inglaterra, y, también, en los Estados Unidos. Un ejemplo es Alfred Kroeber (1876-1960), antropólogo cultural y alumno de Franz Boas, quien se interesó por avanzar el concepto de áreas culturales, desarrollado en su libro: Cultural and Natural Areas of Native North America. La obra se publicó en 1939, precisamente el año en que Covarrubias viaja a San Francisco con-

6. Covarrubias, El águila, el jaguar y la serpiente, 34. En este párrafo, Covarrubias hace referencia a varios antropólogos, etnólogos, sinólogos e historiadores del arte ligados a instituciones como el American Museun of Natural History de Nueva York, el Field Museum of Natural History de Chicago y la Universidad de Chicago. La mayoría eran conocidos por sus trabajos sobre el arte de China y Japón (Fenellosa y H. G. Creel) y otros más por ser pioneros en el campo de la etnología como Leonhard Adam autor de Primitive Art (Harmondsworth, Middlesex: Penguin, 1940, 1949). Es interesante reparar en Berthold Laufer, experto sinólogo, quien desde el Field Museum en Chicago ejerció la curaduría de las colecciones provenientes de China. Laufer estaba interesado en la relación entre culturas y la migración de conocimientos. En un artículo sobre Colón y su idea de China (Cathay), se refiere a un mito kekchi (Guatemala) de un hombre que poseía una piedra mágica por medio de la cual se podía ver todo lo que pasaba en el mundo, la contraparte de la copa del rey Kai Khosrau en el Shahnameh (El libro de los reyes, un poema épico persa del siglo x) en la que se reflejaba el mundo. Para Laufer, el hecho de que los mitos migran de Asia a las Américas, implicaría que puede haber otras transmisiones de elementos culturales como sistemas calendáricos y motivos artísticos. El trabajo que escribió Laufer sobre Colón y Cathay fue hecho para desarrollar la idea de que América y Asia están relacionadas y que el "orientalista" puede contribuir a elucidar una fase temprana de la historia americana. "Colon \& Cathay, and the Meaning of America for the Orientalist", Journal of American Oriental Society 5I, núm. 2 (I93I): 87-IO3. 
tratado para realizar los seis mapas/murales de gran tamańo que lucirían en la feria de San Francisco: Golden Gate International Exhibition bajo el título de Pageant of the Pacific. ${ }^{7}$ Será en la Universidad de Berkeley donde Covarrubias conocerá a Kroeber, quien se desempeñaba como profesor en el Departamento de Antropología, y se acercaría a su idea sobre la dispersión de determinados rasgos culturales que llevan a delimitar la geografía en la que ocurre una distribución de elementos culturales. Las áreas culturales comprenden distintas jerarquías que van desde lo central o nuclear hasta áreas intermedias y periféricas.

En Alemania e Inglaterra se teorizó sobre aquellos centros de origen que se extienden hacia el resto del mundo, y que tuvieron importancia hacia finales del siglo xix y la primera parte del xx. Estas nociones de un centro emisor fueron cambiando de significado.

Sus adeptos fueron etnólogos y algunos viajeros expertos interesados en trasponer el territorio europeo y acercarse a otras culturas por medio de la observación y el coleccionismo, origen de los llamados museos etnográficos. Junto con los antropólogos y etnólogos surge en el campo de la historia del arte la Escuela de Viena que mira hacia otros horizontes como el Medio Oriente y el sudeste de Asia y pone en valor las así llamadas artes menores, especialmente los textiles. Uno de sus logros principales fue salirse del cauce de una historia del arte occidental donde todo origen se ubicaba en el mundo grecolatino.

Si pensamos desde el complejo panorama interesado en explicar el origen y la pervivencia de la cultura, así como su dispersión y conexión con otras culturas, la postura de Covarrubias al afirmar su atracción por las "desviaciones

7. Véase Mónica Ramírez Bernal, El océano como paisaje. Pageant of the Pacific: la serie de mapas murales de Miguel Covarrubias (Ciudad de México: Universidad Nacional Autónoma de México-Instituto de Geografía, 2018). En un artículo referido a los mapas del Pacífico, Alicia Inez Guzmán ve el inicio de su difusionismo en la hechura de los mapas. "Covarrubias creaba murales de acuerdo con la teoría del difusionismo, iluminando un panorama vibrante de objetos y prácticas que, en virtud de su semejanza formal, establecían relaciones desde una perspectiva cultural", "Covarrubias created murals advancing the theory of diffusionism, illuminating a vibrant panorama of objects and practices that by virtue of their formal resemblance, were, in his eyes, culturally related", en "Miguel Covarrubias’s World. Remaking Global Space at the 1939 Golden Gate International Exhibition", en Miguel Covarrubias, Drawing a Cosmopolitan Line, Carolyn Kestner ed. (Austin: Texas University Press, 20I4), 26; Council of National Defence. Coordination of Cultural and Comercial Relations Between the American Republics, I4 de marzo de 194I. Este documento anuncia la inauguración en el AMNH de los mapas de Covarrubias del Pacífico; existe mayor documentación en la que se afirma ya el carácter difusionista de los mapas por parte de Eckholm, en la correspondencia y los documentos que se encuentran en los archivos del AMNH. 
difusionistas subversivas" se refiere en particular al historiador del arte, etnógrafo y arqueólogo Robert von Heine-Geldern (1885-1968), quien desarrolló con bases empíricas y teóricas la noción de contactos entre Asia y Europa, observando y probando sus similitudes. Paul Kirchhoff (1900-I972) definiría a Heine-Geldern como un importante estudioso de las relaciones entre Asia y América. Desafortunadamente, dirá Kirchhoff, a pesar de sus estudios fundamentados en la investigación, éstos fueron rechazados por los americanistas que no tomaron en cuenta sus logros, como por ejemplo: "su comprobación de concordancias a menudo muy detalladas de la técnica del metal y la ornamentación entre los estilos artísticos hindúes y los mexicano". ${ }^{8}$

El obituario/homenaje que Kirchhoff dedicó a Heine-Geldern es del mayor interés, ya que pone de relieve sus aportaciones, y las razones ideológicas y poco científicas por las cuales no tuvo seguidores en América. Sin embargo, fue muy apreciado por Covarrubias a quien Kirchhoff no menciona. En tiempos recientes Kirchhoff está en la mira crítica, a pesar de ser una figura respetada por sus aportaciones a los estudios prehispánicos, entre ellas haber lanzado el concepto de Mesoamérica, asistimos al quizá necesario desmonte del concepto fundamentado en la idea de áreas culturales y más precisamente en el análisis crítico de aquellos trabajos que partían del difusionismo. ${ }^{9}$ Kirchhoff salió de Alemania en los años treinta y pasó una buena parte de su vida en México periodo que interrumpió durante ocho años (1947-1954) para probar suerte académica en los Estados Unidos. En 1949 participó en el XXIX Congreso de Americanistas en el American Museum of Natural History (AMNH), en ese entonces se mantuvo en contacto con Eckholm y Heine-Geldern. Según Jesús Jáuregui, en su artículo “¿Quo Vadis Mesoamérica?”, Kirchhoff desde 1944 tuvo dos líneas de pensamiento evidentes en la escritura de sus artículos: "una no atenta contra la postura de la autoctonía cultural americana, y que es bien vista y, en todo caso discutida y hasta controvertida por la antropología mexicana; y otra línea que postula la derivación civilizatoria americana desde culturas asiáticas, la cual será ignorada y/o rechazada de manera dogmática”. ${ }^{\circ}$

8. Paul Kirchhoff, "Robert von Heine-Geldern (I5 de julio de I885-26 de mayo de 1968)", Dimensión Antropológica, núm. I9 (mayo-agosto 2000):I9I-I99. Disponible en www.dimensiónantropológica.inah-gob.mx, 2.

9. Jesús Jáuregui, “¿Quo Vadis Mesoamérica? Primera parte. Mesoamérica y la discusion de las áreas culturales”, Antropología, Nueva época, núm. 82 (2008): 3-31.

Io. Jáuregui," ¿Quo Vadis Mesoamérica?”, I7. 
Heine-Geldern tuvo que dejar su natal Viena a la llegada del nazismo, se refugió en Nueva York y trabajó durante buena parte de los años cuarenta en el Museo de Historia Natural de dicha ciudad. En el departamento de Antropología del AMNH, Eckholm y Heine-Geldern compartieron perspectivas sobre las relaciones entre Asia y América. Ambos estuvieron cerca de Covarrubias por distintas razones compartiendo dibujos y reforzando, por medio de la observación, las relaciones formales entre culturas diferentes.

Al buscar mayor información sobre "Across the Pacific" — que contribuyó a afianzar la obra comparativa de Covarrubias - ${ }^{\text {II }}$ me encontré con el desalentador panorama de que no existía un catálogo ni una discusión sobre la muestra, tan sólo algunos recortes de prensa. Finalmente pude acercarme a un registro fotográfico de la exposición (fig.I). ${ }^{\mathrm{I2}}$ Esas imágenes me permitieron vislumbrar el proyecto museográfico de Gordon Eckholm, e intuir la participación de Covarrubias y su presencia en el museo. Al mirar las fotografías de la entrada a dicha exposición, pude darme cuenta de que tras las mamparas introductorias asomaban los mapas realizados por Covarrubias con la ayuda de Antonio Ruiz (1892-1964) ${ }^{13}$ para la Feria Internacional de San Francisco en 1939. Este detalle es importante en la medida que reafirma, desde otra perspec-

II. El águila, el jaguar y la serpiente: arte indígena americano iba a constar de tres tomos. El segundo lleva por título Arte indígena de México y Centroamérica. El tercer tomo estaba en ciernes, pero fue interrumpido por la temprana muerte de Covarrubias en 1957. Hay evidencia de este trabajo inconcluso en varios archivos, entre ellos en el Harry Ransom Center en Austin, Texas. Kristaan D. Villela ha trabajado sobre el tema en su artículo "Miguel Covarrubias and Twenty Centuries of Pre-Columbian Latin American Art. From the Olmec to the Inka", en Carolyn Kastner, ed., Miguel Covarrubias, 49-75.

I2. Esto fue gracias a la amabilidad de la bibliotecaria del AMnH, Amy Ritters. La estancia en Nueva York fue posible gracias a la beca Edmundo O'Gorman Scholars Program que me fue otorgada por The Institute of Latin American Studies, Columbia University en Nueva York y Conacyt.

13. Antonio Ruiz (1892-1964) pintor, escenógrafo y dibujante, autor de importantes obras como El sueño de Malinche de 1939 conoció a Covarrubias cuando ambos trabajaron dibujando mapas para la Secretaría de Transportes y Obras Públicas en 1919. Ahí fraguaron una duradera amistad. Y a parte de pedir su colaboración para la feria del Pacífico, Covarrubias invitó a Ruiz a exhibir su obra México I935 en la gran exposición 20 Siglos de Arte Mexicano que abrió en Nueva York en 1940 y en la cual Covarrubias participó como uno de los principales curadores. Véase, Rita Eder, Narraciones: pequeñas historias y grandes relatos en la obra de Antonio Ruiz, El Corcito (Ciudad de México: Universidad Nacional Autónoma de México-Instituto de Investigaciones Estéticas, 2017), 198-202. 


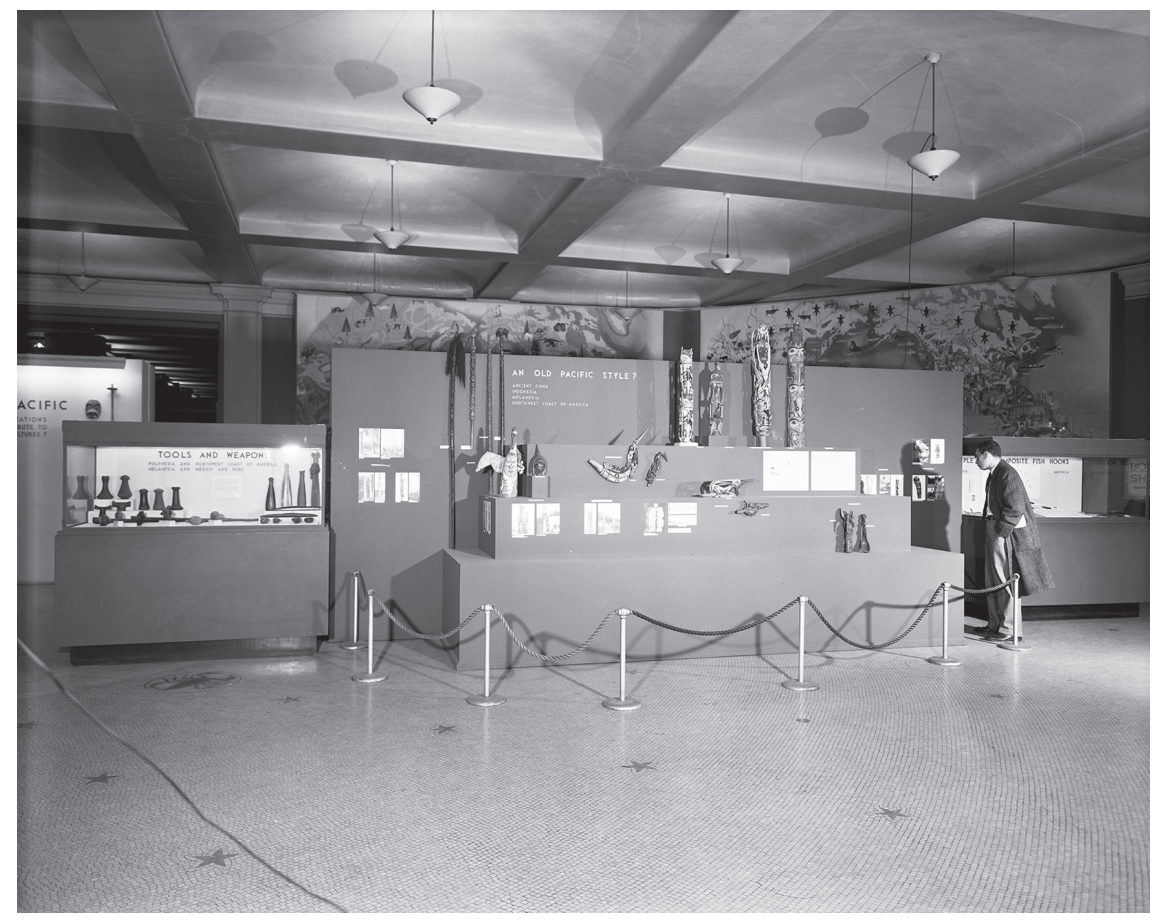

I. Vista parcial de la exposición "Across the Pacific" (A través del Pacífico), 1949, plata sobre gelatina, Museo de Historia Natural de Nueva York.

tiva, su relación con el museo. Si el museo hubiera comprado los mapas, éstos habrían estado en exhibición, cerca de la sala que Franz Boas dedicó a las culturas indígenas de la Columbia Británica; pero esta posibilidad no se concretó debido a la exigencia de Covarrubias de que al adquirir los mapas el museo debía comprometerse a exhibirlos permanentemente. ${ }^{\mathrm{I4}}$

I4. Entre los papeles administrativos relativos al pago de seguros que resguarda la biblioteca del AMnH queda claro que aquellos mapas - de los que no parece haber registro de su ubicación, después de haber viajado a Nueva York desde San Francisco a mediados de los ańos cuarenta- en realidad estuvieron bajo custodia del AMNH hasta 1954. También se advierte en los papeles administrativos del 27 de agosto de 1954, que había la intención de comprar esos mapas (Resolution of the Executive Committee of Pacific House, Biblioteca y archivos del AMNH). Al no poder exhibirlos en forma permanente los mapas se regresaron a Pacific House, San Francisco. 
En la ficha introductoria que Eckholm preparó para presentar la exposición al público explicó que la meta era mostrar — visualmente, mediante la formalas dos posiciones opuestas acerca de la evolución de las culturas americanas: por un lado, su desarrollo independiente y, por el otro, probar la relación de las Américas con los pueblos del Viejo Mundo (refiriéndose a China e India), que hicieron contacto a través del océano Pacífico y dejaron una impronta formal. La exposición — según este texto- no intentaba contestar la pregunta o resolver el dilema, sino poner en paralelo objetos de áreas diferentes que mostraban similitudes y sugerían contactos transpacíficos. ${ }^{\mathrm{I}}$

En aquellas notas que redactó para la exposición, Covarrubias arriesga una hipótesis sobre las semejanzas entre los objetos artísticos de las tribus indígenas de las costas del sur de Alaska y la Columbia Británica, particularmente los tlingit, haida, tsimshian y eyak, con los habitantes de las islas de la Melanesia en el Pacífico Occidental. La evidencia de paralelismos, según la lista de obra, se fundamenta también en la comparación de textiles, bronces, marfiles y afinidades entre motivos y diseños, además de enfatizar en los instrumentos musicales, la decoración dental, la plumaria, la decoración de las casas y canoas, los juegos y cierta similitud en el estilo. Ésta era también la posición de Eckholm, quien afirmaba tener la impresión de estar confrontando variantes del mismo estilo cuyas diferencias se debían a la distancia. ${ }^{16}$

La insistencia sobre el estilo implica la necesidad de proporcionar una evidencia visual, ya que las rutas de las migraciones fue tema de debate. En un artículo escrito por Gordon Eckholm y Robert Heine-Geldern, "Significant Parallels in the Symbolic Arts of Southern Asia and Middle America", presentado en el XXIX Congreso de Americanistas que tanto impresionó a Covarrubias, ${ }^{17}$ los autores formularon una argumentación alrededor de las similitudes entre el juego de los mexicas el patoli, muy parecido en su diseño y cosmovisión (las cuatro partes del mundo) al parchis que se juega en India

I5. Documento mecanografiado de la autoría de Gordon Eckholm, inserto en un fólder sobre la exposición "Across the Pacific"; procede del Department of Anthropology, American Museum of Natural History.

16. Gordon Eckholm, An Old Pacific Style, manuscript, Division of Anthropology Archives, American Museum of Natural History.

17. Robert Heine-Geldern y Gordon F. Eckholm, "Significant Parallels in the Symbolic Arts of Southern Asia and Middle America”, en The Civilizations of Ancient America: Selected Papers of the XXIXth International Congress of Americanist, ed. Sol Tax (Chicago: Chicago University Press, 195I), 299. 
y en gran parte del sur de Asia (figs. 2 y 3). Para Alfred Kroeber, el registro de dos juegos similares con las mismas reglas es sorprendente, pero no suficiente; para él, no era válido argumentar la existencia de relaciones entre culturas tan distintas a partir de un solo ejemplo. Esto alertó a los autores del artículo y decidieron contradecir la idea de una comparación excepcional. Eckholm y Heine-Geldern buscaron otros motivos para fortalecer la hipótesis de contacto que arraigan en varios elementos decorativos existentes en uno y otro continente, entre ellos, la flor de loto frecuente en el sur de la India, particularmente en el templo de Amaravati. Según el artículo, con características muy similares, este motivo también se encuentra en Chichén-Itzá, en el llamado Templo de los Tigres. La similitud formal, insistían, no sólo se da en las flores y las hojas sino en toda la planta, incluido el rizoma o tallo de la raíz que crece en forma horizontal bajo el agua. Mientras que las flores y las hojas se representan en forma naturalista, el rizoma es transformado en una forma decorativa y ondulante y ese mismo motivo está presente en Chichén-Itzá. Es sorprendente, dicen los autores, que en India y Mesoamérica el rizoma, una parte de la planta que no es normalmente visible, se convierta en el elemento básico del motivo, y más aún, que se haya estilizado a la manera de una enredadera. ${ }^{18}$

Lo que llama la atención es el énfasis en el rizoma como elemento destacado en este análisis que arroja cierta luz sobre el difusionismo en tanto modelo epistemológico diferente para entender el tema de las relaciones entre culturas. El rizoma de Deleuze y Guattari ${ }^{19}$ traza una analogía que proviene de la botánica y es contraria a la del árbol (sobre todo el genealógico) como metáfora del conocimiento, pues crece en forma horizontal y se reproduce en forma infinita y desordenada o, como dicen Eckholm y Heine-Geldern, en forma de enredadera (creeper). ${ }^{20}$ La noción filosófica de rizoma reinventa la estructu-

I8. Heine-Geldern y Eckholm, "Significant Parallels in the Symbolic Arts", 30I.

19. Gilles Deleuze y Felix Guattari, Rizoma. Introducción (Valencia: Pre-Textos, 1977).

20. Heine-Geldern y Eckholm, "Significant Parallels in the Symbolic Arts", 303. Los autores mencionan otras analogías relacionadas al rizoma del loto que emerge de la boca de un monstruo marino localizados en Chichén-Itzá o en Bali, un motivo que según estas observaciones sobrevivió hasta tiempos recientes. Ambos antropólogos continúan con otros ejemplos como los atlantes que jugaron un papel importante en el arte de la India, y, en México: en donde Tula es un ejemplo sobresaliente. El trabajo de Heine-Geldern y Eckholm menciona las escaleras flanqueadas por balaustradas de serpientes en el sudeste de Asia y Mesoamérica y muchos elementos más en los que pueden detectarse temas y formas que coinciden, pero estilísticamente parecen diferentes. 


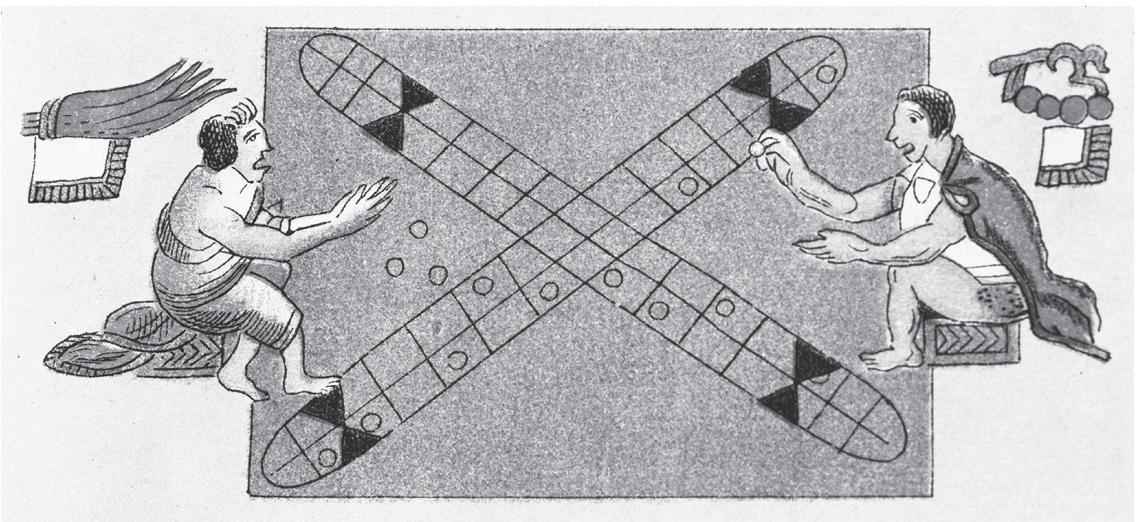

2. Juego del patoli. Imagen de Sahagún incluida en la exposición "Across the Pacific "(A través del Pacifico), 1949, plata sobre gelatina, Museo de Historia Natural de Nueva York.

ra sin principio ni fin y da lugar a un conjunto de conexiones cambiantes que desbordan en cierta forma las limitaciones espacio-temporales.

\section{La migración de los simbolos}

La cronología, la migración de los conceptos formales y una concepción religiosa similar son especulativos. Eckholm y Heine-Geldern ofrecen sugerencias que parten de una investigación con la que intentaron establecer las posibles rutas que hicieron factibles los contactos entre el Viejo y el Nuevo Mundo, siempre en tono hipotético y basándose en la probada capacidad como navegantes de los pueblos del Pacífico. Heine-Geldern fue un apasionado defensor de los contactos entre Asia y las Américas y señalaba la dificultad de deshacer las hipótesis largamente trabajadas sobre estos contactos con base en el análisis del estilo y los motivos:

Any attempt to disprove the role of Asiatic influences in the development of American Indian civilizations would have to take into account the whole complex. It would have to give a plausible explanation for the fact that similar styles and motifs appear in the same chronological order on both sides of the Pacific. So far, no such attempt has been made. ${ }^{2 I}$

2I. Robert Heine-Geldern, "Cualquier intento para refutar el papel de las influencias asiáticas en el desarrollo de las civilizaciones indígenas americanas tendría que tomar en cuenta el 
Finalmente, el argumento de Heine-Geldern para apoyar la tesis de los encuentros entre el sudeste de Asia y las Américas se basará en lo que denominó "el estilo y los motivos" que aparecerán en el mismo orden cronológico en ambos lados del Pacífico. ${ }^{22}$

En esa época había interés por las teorías del estilo y el diseño. Presentaron ponencias sobre estos temas, en el ya mencionado XXIX Congreso de Americanistas: Carl Schuster con el trabajo: "A Significant Correspondence between Old and New World Design" ${ }^{23}$ mientras Alfred Kroeber habló sobre los grandes estilos en el arte de América del Sur. Poco tiempo después Kroeber organizó un gran coloquio sobre el estatus de la antropología como disciplina a mitad del siglo xx e invitó al prominente historiador del arte, Meyer Schapiro para que disertase sobre el tema del estilo justo en el momento en que Covarrubias se encontraba escribiendo El águila, el jaguar y la serpiente. La presentación del historiador del arte de Columbia tuvo por nombre, "Style" y hasta hoy es considerado uno de los más valioso acercamientos al tema. ${ }^{24}$

El congreso dedicado a la antropología fue pensado para responder a ciertas preguntas que provenían de otras disciplinas. Ello llevó a Schapiro a diferenciar las distintas acepciones del estilo y a hacer una especie de doble argumentación, con el fin de que fuese útil tanto para los antropólogos como para los historiadores del arte. Para Schapiro, la aparición inesperada de un estilo en otra región del mundo se podía explicar por medio de las migraciones o el comercio y entenderse como una clave independiente para trazar la genealogía en el tiempo y en el espacio de una obra de arte. "Los estudiosos del estilo" — según este historiador del arte- "han construido un acercamiento sistemático a la distribución temporal y espacial en grandes regiones del mundo mediante la descripción cuidadosa y la comparación cuando sea viable”. ${ }^{25}$ Las reflexiones

complejo en su totalidad. Además, debería proporcionar una explicación plausible de los estilos y motivos similares surgidos en el mismo orden cronológico en ambos lados del Pacífico. Por lo pronto, ninguno de estos intentos se ha logrado", "The Problem of Transpacific Influences in Mesoamerica", en Archeological Frontiers and External Connections, Robert Wauchope, editor de la colección, Eckholm y Gordon E. Willey eds., Gordon F. Handbook of Middle American Indians, vol. 4 (Austin y Londres: University of Texas Press, I966), 295.

22. Heine-Geldern, "The Problem of Transpacific Influences in Mesoamerica", 278.

23. Carlo Severi, El sendero y la voz, 367.

24. Meyer Schapiro, "Style" fue publicado por primera vez en las memorias del encuentro Anthropology Today: An Encyclopedic Inventory, ed. Alfred Kroeber (Chicago: University of Chicago Press, 1953).

25. Meyer Schapiro, "Style", 288. 
de Schapiro se verán influidas por la interdisciplina y escribirá sobre el estilo fuera del canon, en la medida en que, para él, la forma es la respuesta simbólica a las estructuras socioeconómicas y a los estilos de vida. Para Schapiro, hay una cierta diferencia metodológica entre antropólogos e historiadores del arte, la cual estriba en el énfasis en la lectura de la imagen o de lo visual desde su propia estructura, con el fin de lograr un análisis de lo simbólico que ilumine una problemática social que responde a diversas preguntas sobre los modos de producción de las imágenes o las obras escultóricas o arquitectónicas. ${ }^{26}$

En sus reflexiones sobre el estilo, no sorprende que Schapiro dé un espacio a Alois Riegl, uno de los pensadores más representativos de la Escuela de Viena. ${ }^{27}$ Riegl empezó su carrera como historiador del arte en el Museo de Artes Aplicadas e Industrias en esa ciudad. Su trabajo inicial estuvo dedicado al estudio de tapetes orientales que le llevó a concebir la forma en términos de patrones y a pensar esos modelos como parte de un sistema general. Su trabajo, Stillfragen (Cuestiones sobre el estilo), ${ }^{28}$ presenta como argumento principal que el arte no es la transformación de la naturaleza, sino que esa transformación emerge de las formas mismas. Las cuestiones de estilo en Riegl se refieren a lo ornamental que se mueve o se transforma según las necesidades del diseño que determinaron la ornamentación en la Antigüedad. Éste integraba motivos que mostraban variación y simetría, cualidades formales que provenían de la anatomía de las plantas. La vitalidad del diseño interno se manifiesta en la interrelación de los elementos. Con frecuencia Covarrubias y Eckholm mencionaban, además del estilo, la forma y la ornamentación. Para ambos, la com-

26. Thomas Crow, "La inteligencia del arte", en La inteligencia del arte, trad. Laura E. Manríquez (México: Universidad Nacional Autónoma de México-Instituto de Investigaciones Estéticas/Fondo de Cultura Económica, 2008), I5-46. En este artículo Crow comenta la trayectoria de Schapiro y uno de sus trabajos metodológicos fundamentales en "The Sculptures of Souillac", en Medieval Studies in Honor of Arthur Kingsley Porter, comp. Wilhelm R.W. Koelher (Cambridge, Mass.: Harvard University Press, 1939), 359-387.

27. La Escuela de Viena, inaugurada a mediados del siglo xIX, tuvo su auge durante la primera mitad del siglo xx. Historiadores del arte como Julius von Schlosser, Strzygowski, Dvorak y el mismo Riegl le dieron prestigio. Se caracterizó por intentar hacer de la historia del arte una disciplina capaz de eliminar la subjetividad del gusto y la apreciación estética. Su postura se distinguió por marcar la necesidad metodológica precisa mediante la atención a las fuentes históricas. Una de esas metodologías son los estudios comparativos por medio del análisis del estilo. Algunos de sus miembros se inclinaron, como Riegl, por el formalismo sin ocuparse del contenido.

28. Alois Riegl, Problems of Style. Foundations for a History of Ornament, trad. Evelyn Kain, introd. y notas, David Castriota, pról. Henri Zerner (Princeton/ New Jersey: Princeton University Press, 1993). 
patibilidad de las formas cobra enorme importancia en su deseo de enfocar y delimitar las rutas de las migraciones, tema que desarrollaron apoyados en los paralelismos entre objetos de diversa procedencia. En ese sentido, la capacidad de Covarrubias para el dibujo y sus agudas observaciones visuales fueron invaluables para las investigaciones que en ese tiempo se desarrollaban en el Departamento de Antropología del AMNH.

Sobre el tema ha habido importantes variantes y posiciones, entre ellas vale la pena recordar la perspectiva del historiador del arte Rudolph Wittkower (I9OI-I97I), para quien origen y contacto han sido una preocupación constante en la historia del arte. Estos problemas a resolver se acentuarán a finales del siglo XIX cuando inicia el interés por la expansión del horizonte europeo y la mirada se posiciona hacia África, Oriente y las Américas. La razón de este interés para Wittkower es el deseo de estudiar las relaciones entre Europa y las civilizaciones no europeas. ${ }^{29}$

Durante más de un siglo, afirmará, los etnólogos han trabajado con dos teorías antagonistas: por un lado, la difusión de la técnica, ideas, conceptos y formas de arte; por el otro, la noción de que las mismas ideas y formas pueden generarse en culturas ubicadas en distintas partes del mundo. "El historiador de la cultura o del arte que estudia las grandes civilizaciones", advierte Wittkower, "ha aprendido a operar entre los intercambios difusionistas, lo cual no necesariamente anula la posibilidad de convergencia y paralelismo del fenómeno cultural". 30

En este escrito, Wittkower señala la necesidad de comprobar las rutas de contacto y no caer en afinidades superficiales; el término difusión sólo significa que algún producto cultural ha migrado de una civilización a otra. De la misma forma en que migran los productos y los objetos, migran poblaciones enteras, por guerras o conquistas, y también migran los artesanos, comerciantes, viajeros, embajadores, peregrinos y misioneros. Aclarar el asunto de las rutas de la transmisión, dice este historiador del arte, es el primer paso del problema difusionista, ya que debe considerar que el trasplante de las formas, diseños y estilos enfrenta un triple reto: el comercio de los objetos, la migración de los artesanos, y la adaptación y asimilación del material importado. ${ }^{3 \mathrm{I}}$ La posición

29. Rudolph Wittkower, "East and West: The Problem of Cultural Exchange", en Allegory and the Migration of Symbols. The Collected Essays of Rudolph Widower (Nueva York: Thames and Hudson, 1977), 10-24.

30. Wittkower, "East and West: The Problem of Cultural Exchange", Io.

3I. Wittkower, "East and West: The Problem of Cultural Exchange", io. 


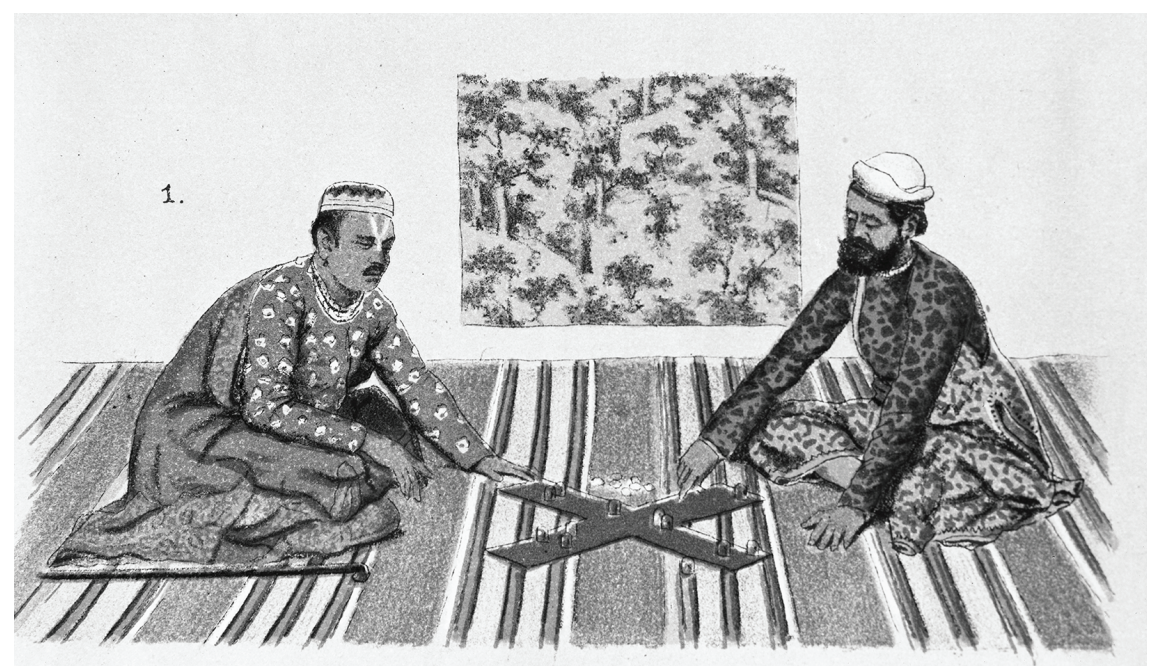

3. Pachisi, juego persa. Imagen incluida en la exposición "Across the Pacific" (A través del Pacifico) 1949, plata sobre gelatina, Museo de Historia Natural de Nueva York.

de Wittkower hace pensar en la importancia que en algún momento tuvo la noción de un mundo conectado y el afloramiento del interés por una historia del arte si no universal, consciente al menos de la incorporación de las culturas no occidentales — por medio de objetos y símbolos_ a la mente y a la vida europea, intentando así percibir cuáles son sus principios formales, cómo se interrelacionan y cómo proyectan un lenguaje visual que pone su sello e identidad sobre la producción artística y al que solemos llamar estilo.

\section{El estilo y el tema de la ornamentación}

En su libro $A$ Wealth of Thought, y particularmente en la larga introducción sobre la teoría del arte primitivo en la obra de Franz Boas, Aldona Jonaitis hace ver la importancia del estilo y el simbolismo como un tema recurrente en el amplio espectro del estudio de las culturas abarcado por el antropólogo alemán. ${ }^{32}$ El conocido libro de Boas Primitive Art incluye ejemplos de Asia, el 
Pacifico, África y Siberia; y el insistente señalamiento de que todos los estudios de los llamados pueblos primitivos debían partir de la cultura, la historia y la psicología del artista para desentrañar el proceso creativo y el desarrollo del estilo. Contra el evolucionismo y el racismo, Boas enfatizaba la diversidad de la historia, la profunda influencia de la difusión y las variaciones estilísticas dentro de los mismos grupos y culturas, además de dar una enorme importancia a la imaginación y a la creatividad. Aceptaba la teoría de Gottfried Semper sobre el origen de lo decorativo en la técnica y le interesaba probar la razón de las semejanzas entre las formas — que adjudicaba a su visión del mundopara lo cual comparaba los complejos diseños geométricos de distintos grupos indígenas de América del Norte que habitaban en diferentes entornos geográficos. Mucho escribió sobre la complejidad de las formas decorativas, y estaba convencido de la importancia de la universalidad de algunas de ellas.

También es importante mencionar el artículo de Boas, "Anthropology", escrito para la Encyclopedia of Social Sciences, en los años treinta. ${ }^{33}$ Ahí, el antropólogo y geógrafo plantea dos métodos para la reconstrucción de la historia de los pueblos sin escritura. Por un lado, la arqueología prehistórica y, por el otro, el estudio comparativo de fenómenos similares. Las formas de vida, dice Boas, las componen el cuerpo y su forma, el lenguaje y la cultura. Las semejanzas en estos intentos comparativos no necesariamente apuntan a un origen común. Muchas veces son sólo formas paralelas de desarrollo y pueden evolucionar en forma independiente.

En un documento encontrado en el archivo Covarrubias en la Universidad de las Américas (UDLA), el antropólogo mexicano transcribe parte del texto de Boas y hace notas y comentarios sobre el concepto de arte en Boas, con un interés especial en la idea de un origen independiente en la consideración del desarrollo de la cultura. ${ }^{34}$ Covarrubias estaría de acuerdo con Boas en posicionar el origen del arte en la influencia del ocio sobre la técnica, y en el placer de dominar el oficio como una de sus fuentes. Sobre la técnica afirma que

A Wealth of Thought: Franz Boas on Native American Art (Washington: University of Washington Press, 1995), 3-37.

33. Franz Boas, "Anthropology", en Encyclopedia of the Social Sciences, ed. general, Edwin R. A. Seligman, ed. asociado, Alvin Johnson, vol. 2, Alliance- Brigandage (Nueva York: The Macmillan Co., 1930 ), 77- 99 .

34. Agradezco a Mónica Ramírez el haberme compartido el documento que procede del archivo Covarrubias que se encuentra en la Universidad de las Américas en la ciudad de Cholula en el estado de Puebla, México. 
es capaz de producir formas que no se encuentran en la naturaleza, como la línea recta, la forma circular o la regularidad con la cual se repiten las curvas o espirales. En ese mismo párrafo hay referencia a las formas fijas por repetición y tradición; estas cualidades de la forma son, según Boas, la base del estilo.

Las anotaciones en rojo hechas por Covarrubias al texto de Boas dicen: "Hay una importante tendencia, no mencionada por Boas, de reducir los objetos de la naturaleza y sus partes a patrones y formas con propósito decorativo o simbólico." Hay ahí, por parte de Covarrubias, una preocupación por acercarse a la problemática de la forma usando la decoración u ornamentación en la cuidadosa observación de la vida de las líneas.

La ornamentación es hoy objeto de debate. En parte, se delinea un análisis crítico ante el legado de la arquitectura moderna, pero también se ha convertido en tema teórico con énfasis en la generación de las formas y su significado. En ese sentido, la figura de Gottfried Semper y su vasto libro sobre el estilo, en el que analiza textiles, cerámica y superficies arquitectónicas, complementa estas referencias en la medida en que su tratado se interesaba en el origen y desarrollo de las formas en el arte y sus leyes internas. Su corpus está constituido por el estudio de las así llamadas artes menores; la idea era obtener de estos artefactos la vida orgánica de su desarrollo y su sentido simbólico. Semper afirmaba que el origen de las líneas curvas era dinámico y no se adhería a ningún sistema fijo de proporciones, sino que estaba sujeto a una constante transformación y al impacto de las fuerzas naturales. La vitalidad desarrollada por un elemento arquitectónico no estaba relacionada con un esquema estructural a priori. ${ }^{35}$

De lo visto hasta aquí queda claro que Covarrubias no fue un caso aislado ni estuvo alejado de las corrientes que conjugan historia del arte, antropología y etnografía, y que están interesadas en el contacto de las culturas y en la universalidad de la dimensión simbólica. Una mirada a la selecta bibliografía que

35. Gottfried Semper, Style. Style in the Technical and Tectonic Arts; or Practical Aesthetics, introd. Harry Francis Mallgrave, trads. Harry Francis Mallgrave y Michale Robson (Los Ángeles: Getty Research Institute, 2004), 80-93. En el debate actual, Jonathan Hay define el ornamento como una dinámica que media entre la naturaleza y el cuerpo humano, y se abre como algo irremplazable para conceptualizar la transferencia que ocurre en el diseño y que lo capacita para atravesar fronteras sin mediar cronología o geografía. El ornamento más allá de copias, influencias o préstamos, ilumina los vectores de la transferencia cultural que se movilizan por la superficie. Todo ello es congruente con la idea de la cultura como fluidez y movimiento y la identidad cultural como el encuentro con lo otro. Jonathan Hay, "The Passage of the Other: Elements for a Redefinition of Ornament", en Gülru Necipoglu y Alina Payne, eds., Histories of Ornament. From Global to Local (Princeton: Princeton University Press, 2016), 67. 
utilizaba muestra su conocimiento del desarrollo de la etnografía y de la antropología en América y en Europa. Entre la diversidad de sus fuentes pueden mencionarse obras relativas al surgimiento de la etnografía a mediados del siglo XIX, que va de la mano de los viajes para recolectar objetos y la consiguiente formación de nuevos museos. Una figura fundadora de la etnografía que interesó en particular a Covarrubias fue la del sueco Hjalmar Stolpe (I84I-I905), quien emprendió importantes estudios comparativos de las culturas americanas. ${ }^{36} \mathrm{~A}$ Stolpe le interesaba sobremanera la ornamentación; Stewart Culin, en un artículo escrito a la muerte de Stolpe, cita una frase del etnógrafo sueco relevante para nuestro tema: "la llave para un acercamiento científico a los objetos etnográficos se encuentra en el estudio comparativo del arte ornamental". ${ }^{37}$

Hay prueba de que Covarrubias consultó y conoció el atlas de Stolpe, Essays in American Ornamentation - a Contribution to the Biology of Ornament. $3^{8}$ Carlo Severi, autor de El sendero y la voz. Una antropología de la memoria ${ }^{39}$ se detiene en todos aquellos que considera pioneros de la biología de las formas. En el espacio que da a la obra de Stolpe, menciona sus grandes viajes y su visita a las colecciones etnológicas de Europa. Con un papel fino y pasteles de cera negra intentaba obtener calcos por frotación en busca de los motivos decorativos que destacaban la representación de la figura humana, lo que lo llevaba a identificar categorías fundamentales de las iconografías primitivas. Stolpe, dice Severi, muestra que la evolución de las formas va más allá de la simple afinidad; esto lleva a pensar que su metodología está involucrada con las propuestas de

36. Carlo Severi, El sendero y la voz. Una antropología de la memoria, introd. José Burucúa, libro electrónico, 20Io. Al igual que Pitt Rivers, Stolpe deseaba crear un museo de etnografía en su país. Como acompañante de la fragata Vanadis, que realizaría un viaje alrededor del mundo — con el fin de obtener material para el museo etnográfico en Suecia-, trajo alrededor de 7,500 piezas de Sudamérica, hizo excavaciones en Ancon en Perú y en el Pacífico Sur, donde investigó los cementerios de Tahití y Oahu y de Japón y las Indias orientales.

37. Stewart Culin, "Hjalmar Stolpe", American Anthropologist 8, núm. I (enero-marzo de 1906): I5O-I56. Las publicaciones de Stolpe se tradujeron al inglés en 1927 en 2 volúmenes e incluían: "Essays in American Ornamentation-a Contribution to the Biology of Ornament" y "On Evolution in the Ornamental Art of Savage Peoples", ambos escritos en 1890, Collected Essays in Ornamental Art, pról. Henry Balfour (Estocolmo: Afonbladets Tryckeri, 1927), I28, I37.

38. Universidad de las Américas, Puebla-Dirección de Bibliotecas-Sala de Archivos y Colecciones Especiales-Archivo Miguel Covarrubias, nota mecanografiada, s.f.

39. Carlo Severi, El sendero y la voz. https://vdocuments.mx/el-sendero-y-la-voz-una-antropologia-de-la- memoria. 
trabajo de un conjunto de disciplinas: antropología, etnografía y arqueología, que cobraron gran auge a mediados del siglo XIX.

En ese momento, y a falta de textos o elementos para el estudio de la memoria escrita, se produjeron textos e imágenes, sobre todo dibujos, que partían del estudio comparativo de las culturas no occidentales y cuyas obras Covarrubias conocía. En su libro, Carlos Severi revisó la importancia de Aby Warburg, Franz Boas, Pitt Rivers y Hjalmar Stolpe; autores que permiten entender algo de la genealogía intelectual de Covarrubias, pues lo muestran profundamente interesado en la comunicación visual: la iconografía, la forma y la ornamentación de las culturas que intentaba comparar. Puede decirse que el proyecto americanista y transpacífico de Covarrubias iba más allá de las metas del momento del nacionalismo cultural en México en las décadas de los años cuarenta y cincuenta y dialogaba con la arqueología de su tiempo en el que la estética no tenía asegurado un lugar. ${ }^{40}$

40. El nacionalismo cultural en México conoció varios momentos importantes. Algunas de sus propuestas fundamentales se tejieron en la década de los años veinte alrededor del movimiento de pintura mural con Vasconcelos al frente. En su libro Mito y profecía en la historia de México (México: Fondo de Cultura Económica, 2004), David Brading intenta entender cómo se construye la historia de México y analiza el papel de José Vasconcelos en la transformación de un pasado reciente en mito político. "La Revolución", dice Brading, "en gran parte gracias a Vasconcelos, ha sido definida como un parteaguas en la vida nacional. Con este filósofo y escritor nace el patronazgo del muralismo y pintores como J.C. Orozco y Diego Rivera pintaban con asombrosa percepción los principales mitos que habían obsesionado al espíritu mexicano desde la llegada de los espańoles". "Más que cualquier texto literario", dice Brading, en lo que parece ser un tono crítico sobre la función de la historia, "son los murales los que resumen y expresan la tradición política mexicana”. Hay un segundo momento directamente relacionado con la fundación del Instituto Nacional de Bellas Artes, en 1946, y la declaración de Miguel Alemán sobre la necesidad de crear y promover un arte plenamente mexicano (véase Tzvi Medin, El sexenio alemanista (México: Era, 1990), I37-I42. Covarrubias no se alineaba con estas ideas y toda su trayectoria indica que su concepción de una cultura nacional era muy diferente a la oficial. Al dedicar un libro, Mexico South (1946), a Oaxaca y al Istmo, saca del centro a la civilización azteca de la misma forma que sus mapas murales de 1939 descentralizan a Europa y colocan al Pacífico como alternativa. Esto también se percibe en su ambición por escribir sobre otras civilizaciones como el libro sobre Bali o la idea de estudiar las culturas indígenas a lo largo del continente. 
DOI: https://doi.org/10.22201/iie.18703062e.2019.mono1.2710

236

RITA EDER

\section{El mapa de Carl Schuster}

Entre las imágenes que revisé en el American Museum of Natural History para intentar recomponer la exposición Across the Pacific encontré un mapa elaborado por Carl Schuster (fig. 4), un historiador del arte egresado de Harvard, visitante incansable de China y, hacia 1935, alumno de doctorado de Josef Strzygowski, quien a su vez pertenecía a la llamada Segunda Escuela de Viena. ${ }^{4}{ }^{\mathrm{I}}$ Este mapa y la trayectoria de Schuster me llevaron a mirar los sistemas comparativos de Eckholm y de Covarrubias en su diversidad de fuentes, ya anotadas en el largo párrafo que dedica a su idea de los contactos culturales transpacíficos. Si bien el antropólogo y dibujante mexicano puso atención sobre todo en las hipótesis de Robert Heine-Geldern, hay otras perspectivas mencionadas, mas no suficientemente explicitadas y que ofrecen un reto para el análisis más complejo del sistema comparativo de Covarrubias.

El tema del diseño y el estudio de las formas dentro de un esquema o modelo comparativo hacen de Carl Schuster una figura relevante por sus repertorios infinitos de diseńos y formas para sustentar la noción de "patrones de contacto", concepto que dio lugar a la publicación de un volumen con los escritos de Carl Schuster editado por el antropólogo Edmund Carpenter en 1997.42

En los primeros años de la década de los años treinta, Schuster emprendió numerosos viajes a China y se concentró en el estudio de los diseños textiles y en la comparación entre objetos de distinta procedencia. Al iniciarse en aquellos años los conflictos bélicos entre Japón y China, Schuster viajó a Austria para realizar un doctorado en la Universidad de Viena bajo la dirección de Joseph Strzygowski, pionero en los estudios de arte islámico y Bizancio. Strzygowski se preguntaba qué es el arte occidental y situaba el origen de sus formas características en el Medio Oriente y no en Roma, con el fin último de encontrar el origen y principio de las formas fuera de Occidente. Éste sin duda era un

4I. Julius von Schlosser, The Vienna School of the History of Art, 32. En este artículo, Julius von Schlosser hace un recuento historiográfico de la Escuela de Viena y se refiere a Strzygowski y a la llamada "Segunda" Escuela de Viena, un proyecto personal de este historiador del arte, disponible en https://arthistoriography.files.wordpress.com/20II/o8/karl-johns-schlosser-transwienerschulerevised.pdf.

42. Carl Schuster, Patterns that Connect: Social Symbolism in Ancient and Tribal Art (Nueva York: Harry Abrams), 1997. Edmund Carpenter fue el editor de esta versión abreviada, previamente había reunido una enorme cantidad de dibujos y textos que publicó en I2 vols., también bajo el título, Social Symbolism in Ancient and Tribal Art (Nueva York: Rock Foundation, 1986-1988). 


\section{DISKS OR PROPS BETWEEN ELBOWS AND KNEES}

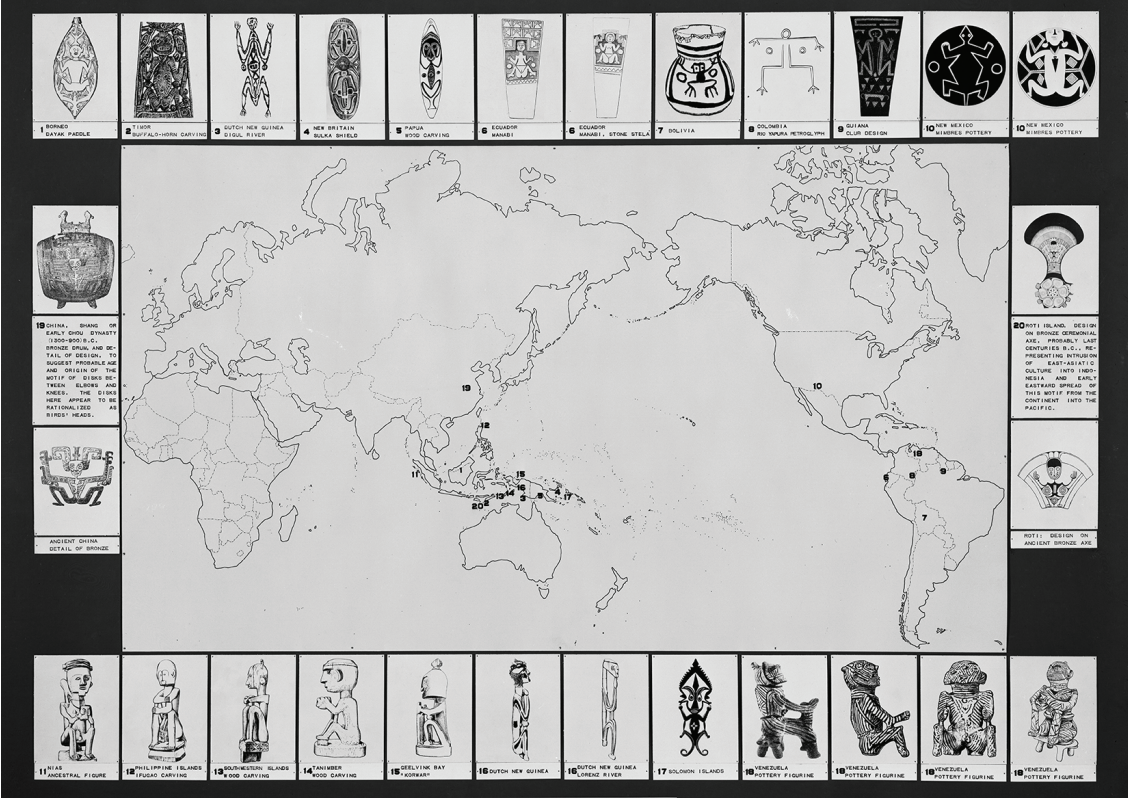

4. Mapa comparativo de Carl Schuster. Imagen incluida en la exposición "Across the Pacific" (A través del Pacifico) 1949, plata sobre gelatina, Museo de Historia Natural Nueva York.

tema controversial, lo mismo que su persona y sus filiaciones ideológicas con el nazismo. Schuster se acercó a Strzygowski con su amplia colección de textiles y, bajo su dirección, terminó su tesis doctoral sobre los bordados de los campesinos chinos. Su metodología, según la propuesta de la Escuela de Viena, exigía un amplio repertorio de símbolos antiguos y los comparaba con motivos similares generados en otra parte del mundo a fin de obtener suficientes pruebas de los contactos debidos a las migraciones. Según Schuster, el arte popular y su simbolismo eran eficaces para rastrear dichos contactos en tanto lenguajes capaces de comunicar las creencias de los pueblos antiguos.

El método consistía en buscar y encontrar los patrones subyacentes que establecían relaciones entre formas aparentemente disímbolas y rastrear la evidencia sin preocuparse por cronologías o fronteras. En diversos artículos, Schuster explicaba las formas de distribución de tipologías de diseño que se presentaban en ambos hemisferios y enfatizaba como asunto fundamental el patrón 
organizativo subyacente. Para él, ese patrón consistía en entender las nociones o conceptos cosmológicos de los cuales se derivaban la función de la decoración del cuerpo, la vestimenta, las herramientas y la noción de vestir al individuo en su ancestralidad tribal. Todo ello se expresaba por medio de un repertorio de formas sobre el cuerpo. Así, los cuerpos podían representarse unidos para mostrar su parentesco o en otros casos se hacía uso de la verticalidad, juntando las extremidades hasta el punto de no reconocer la procedencia anatómica, lo cual contribuía a la complejidad formal que en ocasiones se entendía como si se tratase de formas decorativas. Los mitos establecen la descendencia de piernas, brazos o dedos y es esta noción de origen en las extremidades lo que llevó a Schuster a pensar que esa forma de imaginar el origen humano era una analogía con el mundo natural, en particular el desarrollo de una planta, que concuerda con Riegl y sus preguntas sobre el estilo y la vida de las formas.

\section{El encuentro}

En ocasiones, Schuster estudiaba y escribía en la biblioteca pública de Nueva York y también en el American Museum of Natural History, donde en los años cuarenta se le había facilitado un escritorio y se le patrocinó una exposición de sus fotografías para demostrar justamente la presencia de símbolos compartidos por culturas separadas geográficamente.

La imagen perteneciente a Carl Schuster, que tuve la oportunidad de rescatar en los archivos del American Museum of Natural History, es un mapa cultural (fig.4). En medio del mapa puede apreciarse el mapamundi rodeado de una ancha banda dividida en cuadros donde se van acomodando, por medio de dibujos de objetos, los motivos de diferentes culturas en los cuales hay semejanzas: Borneo, Timor, la Nueva Guinea holandesa, Nueva Bretaña, Papúa, Ecuador, Bolivia, Nuevo México, Colombia. En el lado izquierdo encontramos a China y abajo las islas del Pacífico y Venezuela. Por algunas comparaciones que Schuster pone en su mapa, queda claro que la metodología comparativa de Covarrubias, que se observa en algunos motivos incluidos en El águila, el jaguar y la serpiente, coincide con la de Schuster.

Covarrubias menciona a Carl Schuster, pero es cierto que su atención —al menos en la introducción a El águila, el jaguar y la serpiente-, está puesta en Gordon Eckholm y, sobre todo, en Robert Heine-Geldern. Schuster y Heine-Geldern se habían formado en Viena, aunque tenían distintas formas de 
entender el difusionismo o grados de comprensión de la relación entre Asia y América. En otro trabajo, presentado en el congreso de americanistas de 1939 con el título, "The Problem of Transpacific Influences in Mesoamerica", Heine-Geldern defiende las afinidades estilísticas al comparar la ornamentación en el jade y en el mármol entre diseños mayas y chinos o entre un friso del Tajín y un jarrón de bronce chino. Todo parece indicar que Covarrubias ya estaba convencido de los argumentos de Heine-Geldern y de su idea de lo comparativo, ya que varios dibujos en el trabajo presentado por Heine-Geldern en 1949 son de Covarrubias y están fechados en 1947.

¿Qué propuso Heine-Geldern en aquel congreso que tanto impresionó a Covarrubias? Los mayores obstáculos para legitimar la transferencia de las formas de una cultura a otra eran, en la época en que esto se discutió, las diferencias cronológicas y los procesos de contacto. De acuerdo con el resumen que, en El águila, el jaguar y la serpiente, hace Covarrubias de las ideas de Heine-Geldern, éste se apoya en la hipótesis de las islas de los Mares del Sur como el conducto de la influencia China en América, en diversas épocas y desde variadas fuentes. Para Covarrubias, las diferencias cronológicas no son en realidad obstáculo para la validez de la teoría, ya que la verdadera edad de las civilizaciones americanas, en el tiempo en que Covarrubias escribió el libro, estaba aún por determinarse. Por otra parte, cabía la probabilidad de que las oleadas culturales que arrancaron de Asia en el periodo que va de 1200 a.C. a 200 a.C. se extendieran paulatinamente a lo largo del Pacífico, produciendo sucesivas infiltraciones de estilos, mediante diversos conductos y en épocas distintas; proceso que debió exigir largo tiempo. Por consiguiente, los que viajaban eran los estilos de segunda mano, adquiridos por distintos pueblos y no eran los objetos mismos procedentes de Asia. Covarrubias insiste, que por discutida y herética que pueda ser la teoría de Heine-Geldern, hasta ese momento era la más científica y más correctamente formulada. ${ }^{43}$

El libro de Covarrubias se fundamenta en los motivos que muestran afinidades, como son las figuras en cuclillas y la división bilateral del cuerpo. Los postes totémicos colocados con series verticales o los motivos mitológicos del antiguo estilo del Pacífico, típicos de la costa Noroeste, de Melanesia, de Polinesia (Nueva Zelanda) y de Malasia, o la serpiente con el hocico vuelto hacia arriba y con un rostro humano en la boca, frecuente en Java, India, Bali y Sumatra, comparable con la serpiente de fuego de la piedra solar azteca.

43. Covarrubias, El águila, el jaguar y la serpiente. 
También Covarrubias insiste en los distintos cultos que se encuentran entre Asia, el Pacífico y las Américas, como son el culto a los felinos, a los pájaros y a las serpientes que se encuentran en China, India, Indochina o Indonesia, México y Java, entre otros. Pone un ejemplo que aparece en uno de los trabajos de Heine-Geldern y Eckholm en el que se comparan los templos de Camboya con los del periodo Puuc de Yucatán.

Por el tipo de conexiones y la forma de aproximarse a los objetos, Carl Schuster parece afín a Covarrubias, y, desde luego, hay evidencia de que se conocían e intercambiaban conocimiento y dibujos; ambos participaron junto con Nelson Rockefeller en la fundación del Museo de Arte Primitivo de Nueva York. En un artículo sobre marcas en forma de $\mathrm{V}$ en el pecho, publicado en la revista Anthropos, ${ }^{44}$ Schuster afirma que el propósito de su artículo es llamar la atención sobre cierto diseño que aparece en las culturas tradicionales en ambos lados del Pacífico. Este diseño se encuentra en el sudeste de Asia, en el Pacífico y en las Américas. Este trabajo comparativo sobre las marcas en el pecho se presentó en el ya referido XXIX Congreso de Americanistas y las ilustraciones también formaron parte de "Across the Pacific". Pero es en el mapa encontrado en el American Museum of Natural History donde se muestra la capacidad de síntesis de Schuster cuando relaciona distintas culturas por medio de la forma, lo que en cierto sentido antecede a Covarrubias y los temas que señala en su libro. Sin embargo, queda la duda: ‘acaso Covarrubias influyó en el mapa de Schuster, o viceversa? En todo caso, lo que parece relevante es la diversidad de los enfoques comparativos de la época, los cuales quizá permiten entender mejor el contexto y el interés por el contacto entre culturas.

Covarrubias señala como importantes una serie de motivos que forman parte del mapa cultural que se debe a Schuster; uno de ellos es el höcker (joroba o forma de giba), cuya característica es tener brazos y piernas propios de una rana, motivo característico del Pacífico y típico de China, Malasia e Indonesia. El otro motivo que Schuster utiliza, señalado por Covarrubias, es el que muestra ojos y cara dibujados sobre las articulaciones, que se encuentra en la costa noroeste de México, también entre los mexicas y otros pueblos. ${ }^{45}$

44. Anthropos, Bd. $47 \mathrm{H} \mathrm{1/2}$ (enero-abril, 1952), 99-II8.

45. Covarrubias, El águila, el jaguar y la serpiente, 34. 


\section{Conclusiones}

El primer capítulo, y uno de los más extensos del primer tomo de El águila, el jaguar y la serpiente es precisamente sobre el poblamiento de América o lo que el autor denominó: los orígenes del hombre americano. Dicho capítulo revisa los distintos mitos respecto al problema; desde un lejano origen vikingo, pasando por la Atlántida de Platón hasta las diez tribus perdidas de Israel y otras especulaciones. Covarrubias señala que los estudiosos americanistas están divididos entre difusionistas y aislacionistas; estos últimos, los aislacionistas, definidos por sustentar la idea de que el difusionismo es una corriente de pensamiento que intenta robar la gloria de las contribuciones culturales de América. ${ }^{46}$

El autor reúne la información científica y enfatiza el problema de la edad del hombre americano, repasando la información y los descubrimientos arqueológicos de su tiempo, y haciendo la lectura cuidadosa de códices y mitos americanos. Se vale de la estratigrafía pues es un método de datar la cerámica — que le interesó sobremanera-, de la misma forma en que recurre a la cultura material para dar apoyo a sus datos, y a las ciencias auxiliares, como la dendrocronología, que permite calcular la edad de los árboles, o la prueba del carbono I4, inventada en los tiempos en que escribió su libro.

Los aislacionistas —dice Covarrubias_ hablan de una sola migración por el estrecho de Bering mientras que los difusionistas se dividen en los que creen que la civilización de las Américas proviene en parte del Viejo Mundo y en los que insisten en la existencia de contactos entre Asia y América desde la edad de piedra. Para Paul Rivet y Gladwin que ocupan un lugar prominente en su libro, el Nuevo Mundo fue un lugar de afluencia de una enorme variedad de culturas que llegaron a lo largo del océano Pacífico y que se establecieron en las costas de América. Covarrubias se basa en el libro de Paul Rivet, Los orígenes del hombre americano, y menciona la hazaña del Kon Tiki, a cargo de Thor Heyerdhal, bien conocida en su tiempo y altamente revalorada en la actualidad. A Covarrubias le interesaba la idea de "las Américas" como aglutinadoras

46. Su trabajo da cuenta de la larga lista de descubrimientos de la Antigüedad del hombre americano y pasa revista a todo aquello encontrado a lo largo de las Américas. Todos estos restos, dirá Covarrubias, han probado que la heterogeneidad es la característica más sobresaliente, en la medida en que hay restos de cerebros con distintas formas, como son los mongoloides, australoides y aun negroides. 
de la diversidad cultural, un continente de una enorme diversidad de capas culturales, un lugar del encuentro por excelencia.

Resulta imposible cerrar la discusión del origen del hombre americano en la medida en que la ciencia avanza y el ADN permite nuevas posibilidades. En el mes de enero de 20I8, análisis de ADN aplicados a los restos de una nińa recién nacida (seis semanas de edad) de II,500 años de antigüedad hallados en Alaska en 20I3, arrojan nueva luz sobre el poblamiento de América. Estudios genéticos de la criatura junto con otros datos indican que pertenecía a un grupo humano hasta ahora desconocido. Los científicos aseguran que el análisis del ADN apoya la idea de que una gran ola de migrantes se mudó al continente desde Siberia, hace más o menos 20,000 años. Los niveles del mar pudieron haber decrecido y dado lugar a una porción de tierra seca en el estrecho de Bering, estas grandes áreas de tierra se sumergieron de nuevo cuando inmensas porciones de hielo se derritieron. Los pioneros son los ancestros de los nativos americanos. Éstos son los restos humanos más antiguos encontrados en Alaska.

El asunto de mayor interés consiste en que los restos de esta niña pertenecen a un tipo humano diferente, lo que apunta a la existencia de una población ancestral que empezó a ser genéticamente distinta en el este de Asia hace 34,000 años y que completó la diferenciación hace 25,000 años aproximadamente. El análisis sugiere que un grupo de antiguos beringianos, representado por los restos de la niña recién nacida en Upward Sun River (USRI), en algún momento empezaron a diferenciarse de los migrantes pioneros. Ahí, según este científico, se produjeron dos grupos genéticos que son reconocidos como los ancestros de las poblaciones indígenas actuales.

De acuerdo a este trabajo, antes de este genoma sólo teníamos conocimiento de una población americana y siberiana más reciente y ahora con este descubrimiento hay la posibilidad de entender mejor su divergencia con otros grupos humanos y su antigüedad. ${ }^{47}$

Para Covarrubias esta información hubiera sido de gran valor y hubiese ampliado las hipótesis que aparecen en la parte de su libro llamada "Los orígenes del hombre americano". Sin embargo, como he argumentado, la fuerza de la propuesta de El águila, el jaguar y la serpiente radica en cómo problematizó

47. V.J. Moreno-Mayar, L. Vinner, B.A. Potter, S. Rasmussen, M. Steinrücken, J.A. Kamm, J. Terhorst, A. Malaspinas, A.S. Albrechtsen, M. Reuther, J.D. Sikora, J.D. Malhi, R.S. Irish, L. Song, Y.S. Orlando, R. Meltzer, D.J. Nielsen y Eske Willerslev. "Terminal Pleistocene Alaskan Genome Reveals First Founding Population of Native Americans", Nature (II de enero de 2018): 553, 203-207. Disponible en www.nature.com/articles/nature25173. 
en dibujos y textos la relación entre antropología e historia del arte. El cruce entre estas dos disciplinas actuó como punto de partida para plantear un camino hacia el análisis estético de culturas no occidentales, de distinta procedencia, pero hermanadas en la forma. Lo que más importaba a este artista visual y antropólogo era destacar la capacidad de los otros — a los que se rehusaba a llamar primitivos - de producir belleza desde una espiritualidad diferente y estilos de vida evocados en objetos de alta complejidad simbólica.

En su breve, pero intensa vida, destacó el amor por los viajes y la naturalidad para establecer una red de contactos internacionales. Covarrubias se sentía en casa en todos los lugares donde se asentaba por un tiempo, y no parecía sentirse extraño fuera del lugar en donde nació. Se trataba de un experto observador que se apropió de todo lo que pudiera culturalmente ser ajeno, pero también era conocedor de lo suyo y, con ese bagaje encontró alternativas a las barreras del nacionalismo y su tendencia aislacionista. Él intensificó su talento como escritor y antropólogo en una Europa convulsionada por el ascenso de los fascismos que desembocarían en la segunda guerra mundial; quiso entender el mundo desde otro horizonte y encontró en el difusionismo un abanico de posibilidades para entretejer las afinidades de la creación artística y modelos de vida diferentes a los occidentales. La idea de Covarrubias, ciertamente, no era apegarse en forma irrevocable al difusionismo, pero sí insistir, dada su propia postura cosmopolita, en que el mundo - en particular el suyo que se revela en obras como Mexico South ${ }^{48}$ y poco más tarde en la ambiciosa obra de la interconexión de las culturas indígenas de las América一, no participa de una construcción del poder donde predomina lo fijo y lo monumental, sino que se inclina por la interacción permanente de los artefactos y objetos en el complejo universo de las formas y su capacidad de desplazarse. \$ 